\title{
Analysis of magnetic data of ground station network during strong magnetic storms
}

\author{
Oksana Mandrikova ${ }^{1,2^{*}}$, Igor Solovev ${ }^{1}$, Sergey Khomutov $^{1}$, Dmitry Baishev ${ }^{3}$, Phani \\ Chandrasekhar ${ }^{4}$ \\ ${ }^{1}$ Institute of Cosmophysical Research and Radio Wave Propagation FEB RAS, 684034 Kamchatka \\ region, Elizovskiy district, Paratunka, Mirnaya str., 7, Russia \\ ${ }^{2}$ Kamchatka State Technical University, 683003 Kamchatka region, Petropavlovsk-Kamchatskiy, \\ Kluchevskaya st., 35, Russia \\ ${ }^{3}$ Yu. G. Shafer Institute of Cosmophysical Research and Aeronomy SB RAS, 677980 Yakutsk, Lenin \\ Ave., 31, Russia \\ ${ }^{4}$ CSIR-National Geophysical Research Institute, Telangana, Hyderabad -500007, India
}

\begin{abstract}
The paper suggests a new technique for magnetic data analysis to detect and to estimate short-time anomalous increases in geomagnetic disturbance intensity. Based on the technique and applying the data of meridionally arranged stations in the north-east of Russia («Kotel'nyi» KTN, «Tixi» TIX, «Chokurdakh» CHD, «Zyryanka» ZYK, «Mys Shmidta» CPS, «Yakutsk» YAK, «Magadan» MGD, «Paratunka» PET, «Khabarovsk» KHB) and the near equatorial Indian stations ("Hyderabad" HYB and "Choutuppal" CPL), we analyzed the geomagnetic field variations during strong magnetic storms. This approach allowed us to detect simultaneously occurring local increases in geomagnetic activity observed a few hours before events and during the main phases of magnetic storms.

The development of the method was supported by RSF Grant No.14-1100194. Experimental investigations were supported by RFBR Grant No. 16-55-45007.
\end{abstract}

\section{Introduction}

The work is focused on the development of methods for the research of dynamic process in the magnetosphere during increased solar activity and magnetic storms. The influence of solar activity on the Earth's magnetosphere is very complex, many aspects of which have not been sufficiently studied so far [1]. The state of the magnetosphere is an important factor of cosmic weather, which affects many aspects of our life. Therefore, researches in this area have great scientific and practical interest [1-3].

\footnotetext{
*Corresponding author: oksanam1@mail.ru
} 
The magnetic field variations have a complex structure, and they consist of non-smooth local features of varying amplitude and duration in disturbed periods [1-7]. Analysis of formed local structures allows us to receive the information about the intensity and dynamics of geomagnetic disturbance development in the detail [2-7]. The traditional approaches and methods of time series analysis are not sufficiently effective to solve this problem [8-10]. At the present time, modern mathematical methods and information technologies in this field are intensively developing [2-7, 11-17]. Algorithms to isolate the interferences during the primary processing of magnetic data [2, 13] and methods for the anomaly detection during magnetic storms [2, 13] were developed on the basis of DataMining approaches. It is possible to optimize the process of geophysical data registration and the global databases formation. Authors [12] proposed an algorithm for the interplanetary magnetic field processing and the Dst-index computation by neural networks. Authors of the present paper developed a method for magnetic data analysis based on the wavelet transform [4, 18]. The method allows them to receive the information about the dynamics of geomagnetic field disturbances during magnetic storms. At the present time, the wavelet transform is widely used in the tasks of magnetic data analysis $[6,15-17,19$, 20]. In the work [19], the wavelet transform is used to study the connection between shortperiod oscillations of the geomagnetic field, the parameters of the solar wind and the interplanetary field during magnetic storms. Problems of removing noise and eliminating the periodic component of the field caused by the Earth rotation are solved on the basis of the wavelet transform $[16,17]$. Automatic algorithm to determine the periods of the initial phase of a magnetic storm based on the discrete wavelet transform was proposed (15). On the basis of the wavelet spectrum analysis of the geomagnetic field variations, a method for prediction of strong geoeffective solar flux was proposed in the paper [6]. In the present paper, the authors used the continuous wavelet transform and the wavelet packet to analyze the geomagnetic field variations during strong magnetic storms and to obtain a pattern of distribution and dynamics of disturbances in the analyzed areas. In the analysis we used data from the meridionally located stations in the northeast of Russia («Kotel'nyy» KTN, «Tixie» TIX, «Chokurdakh» CHD, «Zyryanka» ZYK, «Mys Schmidta» CPS, «Yakutsk» YAK, «Magadan» MGD, «Paratunka» PET, and «Khabarovsk» KHB) and data from the near-equatorial Indian stations. The paper shows the application of developed computational solutions, which allows us to study small-scale shot-period changes (from a few seconds to tens of minutes) in the geomagnetic field parameters and long-period variations (from several hours to several days) of the complex structure. During the data processing, features of disturbances, describing active large-scale processes in the magnetosphere during the storms were detected in dynamics. Weak increases of the geomagnetic activity occurring synchronously on the eve of the events and possibly associated with approaching storms were detected.

\section{Methods of data analysis}

\subsection{Isolation and estimation of the geomagnetic disturbance intensity}

Using the continuous wavelet transform, which is defined by equation [21, 22]:

$$
\left(W_{\Psi} f\right)(b, a):=|a|^{-1 / 2} \int_{-\infty}^{\infty} f(t) \Psi\left(\frac{t-b}{a}\right) d t
$$


where $\Psi$ is a wavelet, $f \in L^{2}(R), a, b \in R, a \neq 0$, we can obtain the detailed information about the properties of the function $f$. Wavelet $\Psi$ is a window function and has a zero mean and, when the scale $a$ tends to be zero, coefficients $\left(W_{\Psi} f\right)(b, a)$ describe the properties of the function $f$ in the neighborhood of $t=b$.

If at time $t=b$ a local singularity arises in the function, the absolute values of the wavelet coefficients in the neighborhood $t=b$ increase. To isolate the local features, a threshold function can be applied $[4,5,18,23]$ :

$$
P_{T_{a}}\left(W_{\Psi} f_{b, a}\right)=\left\{\begin{array}{l}
W_{\Psi} f_{b, a}, \text { если } \quad\left(W_{\Psi} f_{b, a}\right) \geq T_{a} \\
0, \text { если }\left|W_{\Psi} f_{b, a}\right|<T_{a} \\
-W_{\Psi} f_{b, a}, \text { если }\left(W_{\Psi} f_{b, a}\right)<-T_{a}
\end{array},\right.
$$

where $\quad T_{a}=U^{*} S t_{a}{ }_{a} \quad$ is the threshold function where $S t^{l}{ }_{a}=\sqrt{\frac{1}{l-1} \sum_{k=1}^{b}\left(W_{\Psi} f_{b, a}-\overline{W_{\Psi} f_{b, a}}\right)^{2}}$, is the standard deviation calculated within the time window of the length $l, \overline{W_{\Psi} f_{b, a}}$ is the average value calculated within the time window of length $l, U$ is the threshold coefficient.

If we consider the variations of the magnetic field as $f$, then the absolute values of wavelet coefficients

$$
e_{b, a}=\left|\left(W_{\Psi} f\right)(b, a)\right|
$$

characterize deviation of the field variation from its characteristic level on the scale $a$ at time $t=b$ [23]. Since the magnitude of the deviation of the magnetic field variation from its characteristic level serves as a measure of the degree of its perturbation $[1,1,3,5,8-10$, 17], application of operation (1) makes it possible to isolate the periods of increasing geomagnetic activity. Then the intensity of field perturbations at time $t=b$ can be estimated as

$$
E_{b}=\sum_{a} P_{T_{a}}\left(W_{\Psi} f_{b, a}\right)
$$

In the case of field positive disturbances (current variation increase relatively the characteristic level), the value

$$
e_{b, a}^{ \pm}=\left(W_{\Psi} f\right)(b, a)
$$

is positive $\left(e_{b, a}^{+}\right)$. In the case of field negative disturbances (variation decrease relatively the characteristic level), the value is negative $\left(e_{\bar{b}, a}\right)$. Then the intensity of the positive and negative disturbances of the field at time $t=b$ can be estimated, respectively, as

$$
E_{b}^{+}=\sum_{a} P_{T_{a}}\left(e_{b, a}^{+}\right),{ }_{\text {и }} E_{b}^{-}=\sum_{a} P_{T_{a}}\left(e_{b, a}^{-}\right) .
$$


The parameters of function (1), the window length $l$ and the threshold coefficient $U$ are adaptive, and determine the size of a time window within which geomagnetic disturbances are estimated and determine the size of a time window within which we estimate the geomagnetic disturbances and the intensity of isolated geomagnetic disturbances. Application of adaptive parameters of the threshold function allows us to identify both short-term insignificant increases in geomagnetic activity that can be observed on the eve of magnetic storms (Fig. 1) and longer strong increases during magnetic storms (Fig. 2).

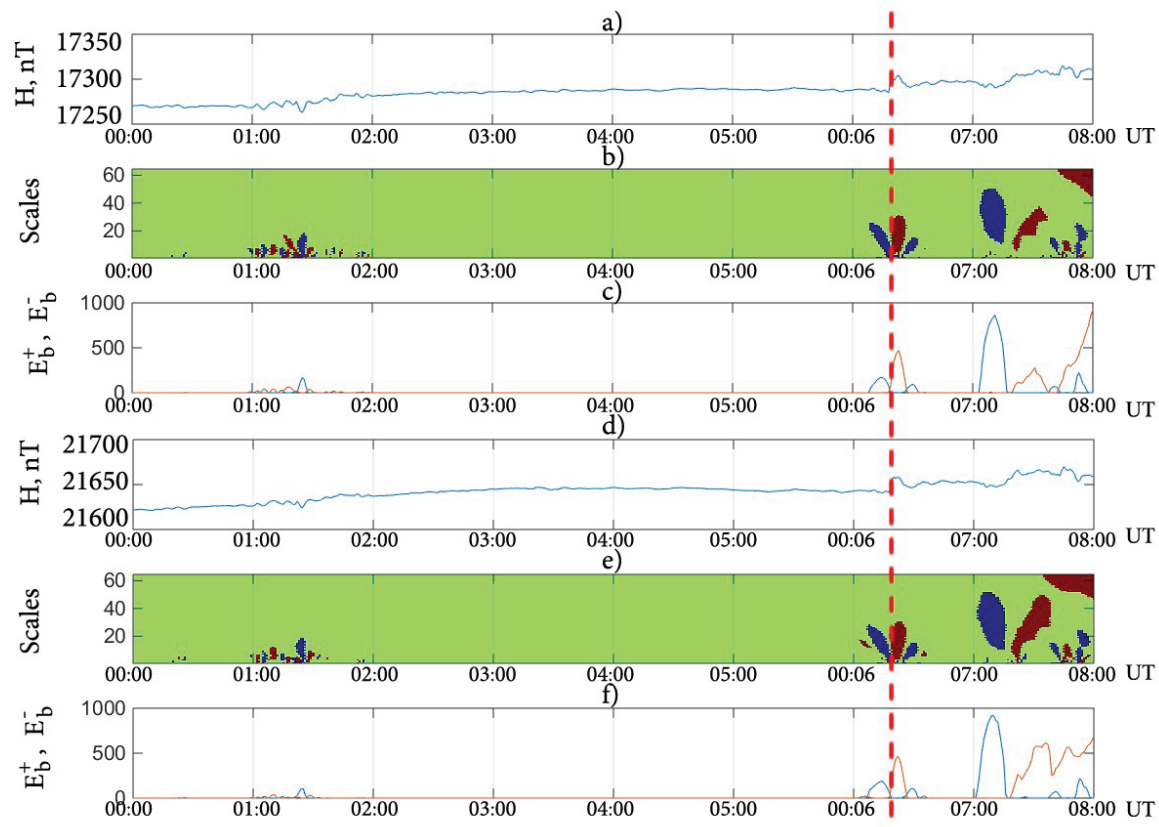

Fig. 1 Results of data processing for January 7, 2015 from 00:00 UT to 08:00 UT (the parameters of the threshold function $\mathrm{l}=720, \mathrm{U}=3$ ): a) H-components of the Earth's magnetic field (Magadan); b) result of application of operations (1) (Magadan); c) result of application of operations (1), (5) (Magadan) positive disturbances are indicated by red line, and negative disturbances are indicated by blue line; d) H-components of the Earth's magnetic field (Paratunka); e) result of application of operations (1) (Paratunka); f) result of application of operations (1), (5) (Paratunka) positive disturbances are indicated by red line, and negative disturbances are indicated by blue line; The dashed line indicates the beginning of the magnetic storm 


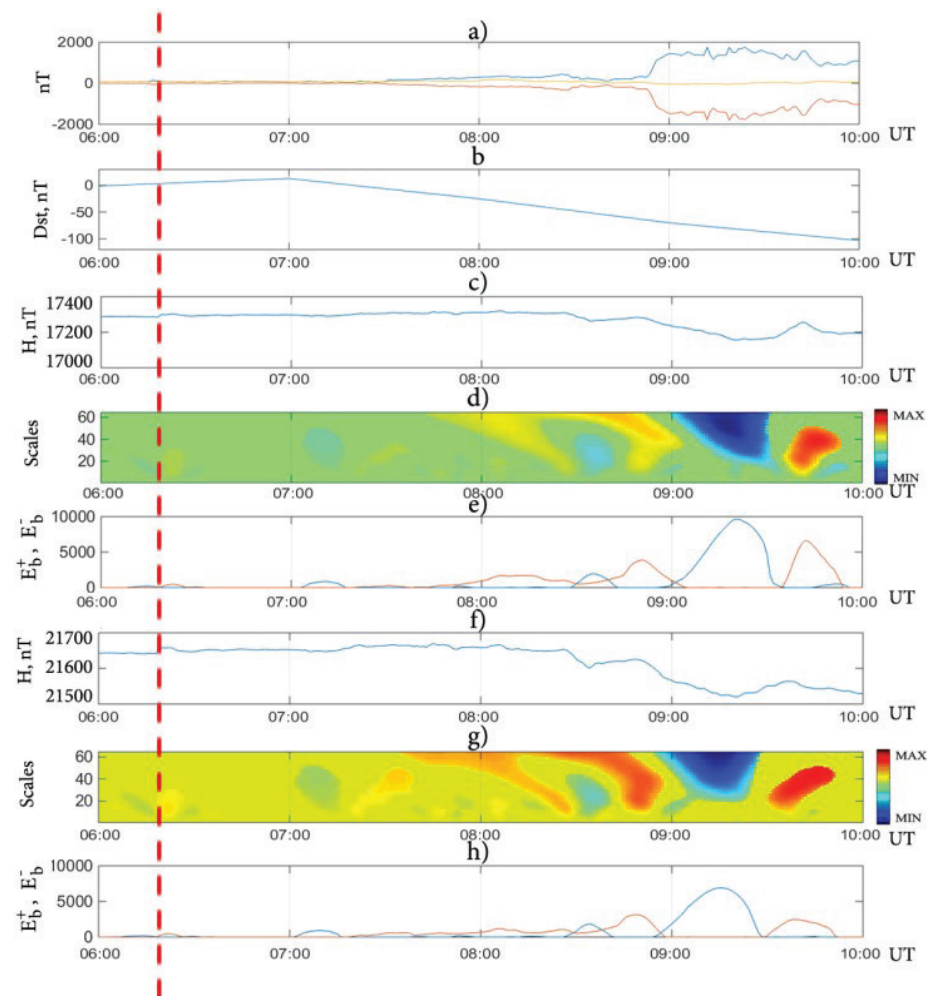

Fig. 2 Results of data processing for January 7, 2015 from 06:00 UT to 10:00 UT (the parameters of the threshold function $l=720, \mathrm{U}=3$ ): a) H-components of the Earth's magnetic field (Magadan); b) result of application of operations (1) (Magadan); c) result of application of operations (1), (5) (Magadan) positive disturbances are indicated by red line, and negative disturbances are indicated by blue line; d) H-components of the Earth's magnetic field (Paratunka); e) result of application of operations (1) (Paratunka); f) result of application of operations (1), (5) (Paratunka) positive disturbances are indicated by red line, and negative disturbances are indicated by blue line; The dashed line indicates the beginning of the magnetic storm

\subsection{Extraction of geomagnetic pulsations}

To extract geomagnetic pulsations, following the results of $[4,18]$, we used the expansion of the geomagnetic field variation into wavelet packets:

$$
\begin{aligned}
& f_{(0,0)}(t)=\sum_{n} c_{j, k, n} \varphi_{j, k, n}(t)+\sum_{(j, k) \in D_{i}} \sum_{n} d_{j, k, n} \Psi_{j, k, n}(t)+ \\
& +\sum_{(j, k) \notin D_{i}} \sum_{n} d_{j, k, n} \Psi_{j, k, n}(t)=f_{\text {trend }}(t)+f_{\text {dist }}(t)+e(t)
\end{aligned}
$$

where $\varphi_{j, k}=\left\{\varphi_{j, k, n}\right\}_{n \in Z}$ is basis in the node $(j, k)$ of a wavelet packet tree obtained by a scaling function; $\Psi_{j, k}=\left\{\Psi_{j, k, n}\right\}_{n \in Z}$ is the wavelet-basis in the node $(j, k)$ of the wavelet packets tree; coefficients $c_{j, k, n}=\left\langle f, \varphi_{j, k, n}\right\rangle ; d_{j, k, n}=\left\langle f, \Psi_{j, k, n}\right\rangle ; D_{i}$ is s set of index pairs, $(j, k)$ is a node of the wavelet packet tree, where $j$ is the scale, $\mathrm{k}$ is the number of the 
component, the subscript $(0,0)$ indicates the origin of the discrete data belonging to the node of the tree with indices $(0,0)$ (it is assumed without loss of generality).

Component $f_{\text {trend }}(t)=\sum_{n} c_{j, k, n} \varphi_{j, k, n}(t)$ in quiet periods describes the trend of the geomagnetic field variation, component $f_{\text {dist }}(t)=\sum_{(j, k) \in D_{i}} g_{j, k}(t)$, where $g_{j, k}(t)=\sum_{n} d_{j, k, n} \Psi_{j, k, n}(t)$ in disturbed periods describes pulsations from a range determined by a set of indexes $D_{i}$. Component $e(t)=\sum_{j \notin D_{i}} \sum_{n} d_{j, k, n} \Psi_{j, k, n}(t)$ is taken as noise.

In this work, in order to extract the pulsations in the ranges Pi1, Pi2 and Pi3, we used the decomposition into wavelet packets according to the scheme shown in Gig. 3. In accordance with the scheme in Fig. 3, we obtain sets of index pairs $D_{1}=\{(1,1) ;(2,1) ;(2,2) ;(3,1) ;(4,1) ;(5,1)\} \quad D_{1}=\{(6,1) ;(7,1)\} \quad D_{1}=\{(8,1) ;(9,1)\}$ Fig. 4 shows an example of extraction of pulsations Pi1 and Pi2 during the magnetic storm on January 7, 2015.

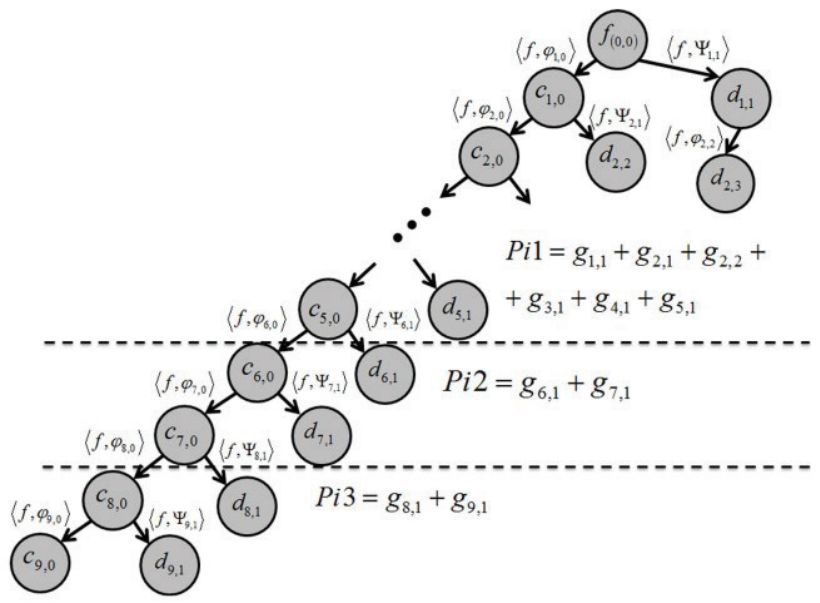

Fig. 3 Components of the wavelet packet containing disturbances in the ranges Pi1 - Pi3

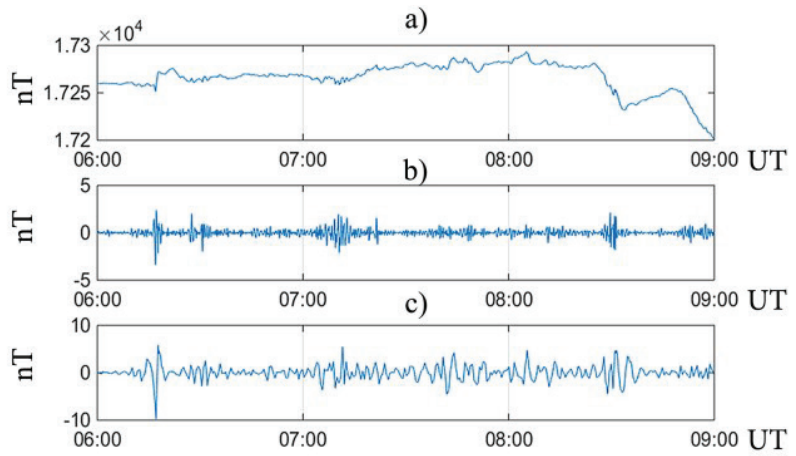

Fig. 4. Result of pulsation extraction on the basis of wavelet packets: a) H-component of the Earth's magnetic field; b) extracted disturbances in the range of pulsations Pi1; c) extracted disturbances in the range of pulsations Pi2 


\section{Results of data processing and analysis}

Data processing and analysis for the station network in north-east of Russia (Table 1) were carried out using the developed method. To analyze the processes in the magnetosphere at equatorial latitudes, we used the data of Indian stations, HYB "Hyderabad" and CPL "Choutuppal" (Table 1). The results of data processing during the magnetic storm on January 7, 2015 are presented below in detail. The results of data processing during strong magnetic storms, occurred in 2015, are presented in Table 1.

Table 1. Observatories of the north-eastern segment of Russia.

\begin{tabular}{|l|c|c|c|c|c|c|}
\hline Observatory & $\begin{array}{c}\text { IAGA } \\
\text { code }\end{array}$ & $\begin{array}{c}\text { Geo- } \\
\text { graphic } \\
\text { latitude }\end{array}$ & $\begin{array}{c}\text { Geo- } \\
\text { graphic } \\
\text { longitude }\end{array}$ & $\begin{array}{c}\text { Geo- } \\
\text { magnetic } \\
\text { latitude }\end{array}$ & $\begin{array}{c}\text { Geo- } \\
\text { magnetic } \\
\text { longitude }\end{array}$ & $\begin{array}{c}\text { Local Time } \\
\text { (LT) }\end{array}$ \\
\hline Kotel'nyy (1) & KTN & $76^{\circ} 00.0^{\prime}$ & $137^{\circ} 52.6^{\prime}$ & $66^{\circ} 44.4^{\prime}$ & $162^{\circ} 00^{\prime}$ & UTC +09 \\
\hline $\begin{array}{l}\text { Chokurdakh } \\
(1)\end{array}$ & CHD & $70^{\circ} 37.0^{\prime}$ & $147^{\circ} 52.6^{\prime}$ & $62^{\circ} 8.4^{\prime}$ & $152^{\circ} 36^{\prime}$ & UTC+11 \\
\hline Tixie (1) & TIX & $65^{\circ} 44.2^{\prime}$ & $150^{\circ} 53.0^{\prime}$ & $54^{\circ} 16.2^{\prime}$ & $146^{\circ} 14^{\prime}$ & $\mathrm{UTC}+09$ \\
\hline Yakutsk(1) & YAK & $62^{\circ} 02.1^{\prime}$ & $129^{\circ} 42.1^{\prime}$ & $52^{\circ} 26.4^{\prime}$ & $163^{\circ} 13^{\prime}$ & $\mathrm{UTC}+09$ \\
\hline Magadan (2) & MGD & $59^{\circ} 33.1^{\prime}$ & $150^{\circ} 48.3^{\prime}$ & $51^{\circ} 32.4^{\prime}$ & $146^{\circ} 2.4^{\prime}$ & $\mathrm{UTC}+11$ \\
\hline $\begin{array}{l}\text { Paratunka } \\
\text { Petropavlovs } \\
\text { k- } \\
\text { Kamchatskiy) } \\
(2)\end{array}$ & PET & $52^{\circ} 58.3^{\prime}$ & $158^{\circ} 15.0^{\prime}$ & $45^{\circ} 51.6^{\prime}$ & $137^{\circ} 57^{\prime}$ & $\mathrm{UTC}+12$ \\
\hline $\begin{array}{l}\text { Khabarovsk } \\
(2)\end{array}$ & KHB & $48^{\circ} 29.0^{\prime}$ & $135^{\circ} 04.0^{\prime}$ & $39^{\circ} 15^{\prime}$ & $15^{\circ} 48.6^{\prime}$ & $\mathrm{UTC+10}$ \\
\hline $\begin{array}{l}\text { Hyderabad } \\
(3)\end{array}$ & HYB & $17^{\circ} 22^{\prime} 00^{\prime}$ & $78^{\circ} 28^{\prime} 00^{\prime}$ & $8^{\circ} 50^{\prime} 00^{\prime}$ & $151^{\circ} 78^{\prime} 00$ & $\mathrm{UTC}+5: 30$ \\
\hline $\begin{array}{l}\text { Choutuppal } \\
(3)\end{array}$ & $\mathrm{CPL}$ & $17^{\circ} 17.33^{\prime}$ & $78^{\circ} 55^{\prime}$ & $8^{\circ} 37.2^{\prime}$ & $152^{\circ} 34.8^{\prime}$ & $\mathrm{UTC}+5: 30$ \\
\hline
\end{tabular}

Note. Observatory affiliation is indicated in parentheses: (1) - IKFIA SB RAS, (2) IKIR FEB RAS, (3) - CSIR-National Geophysical Research Institute.

The analyzed event on January 7, 2015 was caused by a coronal emission of solar matter (CME on January 4, http://ipg.geospace.ru/space-weather-review/). The storm had a classical nature with clearly expressed main phases in the Dst-variation (Fig. 5c). Fig. 5 shows the results of disturbance detection and estimation of their intensity from 06.01.2015 to 07.01.2015 (operations (1) and (5) were applied with the values of the threshold function parameters $l=1440$, which corresponds to 24 hours, $U=3$ ). The analysis showed a smooth increase of the geomagnetic disturbance intensity (Figure 5b) during the initial phase of the storm, and the Dst-index had positive values. The disturbance intensity reached the maximum during the period of a significant decrease in Dst-index and increase in the $\mathrm{AE}$ and $\mathrm{AL}$ indexes characterizing the occurrence of an intense substorm in the auroral zone.

The results of detection of $\mathrm{Pi} 2$ and Pi3 pulsations (see the diagram in Figure 3) showed that they occurred at the beginning of the magnetic storm at all the stations under analysis. The highest intensity of the pulsations in the initial phase of the storm was observed at the stations located to the south. At the end of the storm main phase, the intensity of Pi2 and Pi3 pulsations increased at high latitude stations and near the auroral zone, and the values of $\mathrm{AE}$ and $\mathrm{AL}$ indexes simultaneously increased (Fig. 6). 


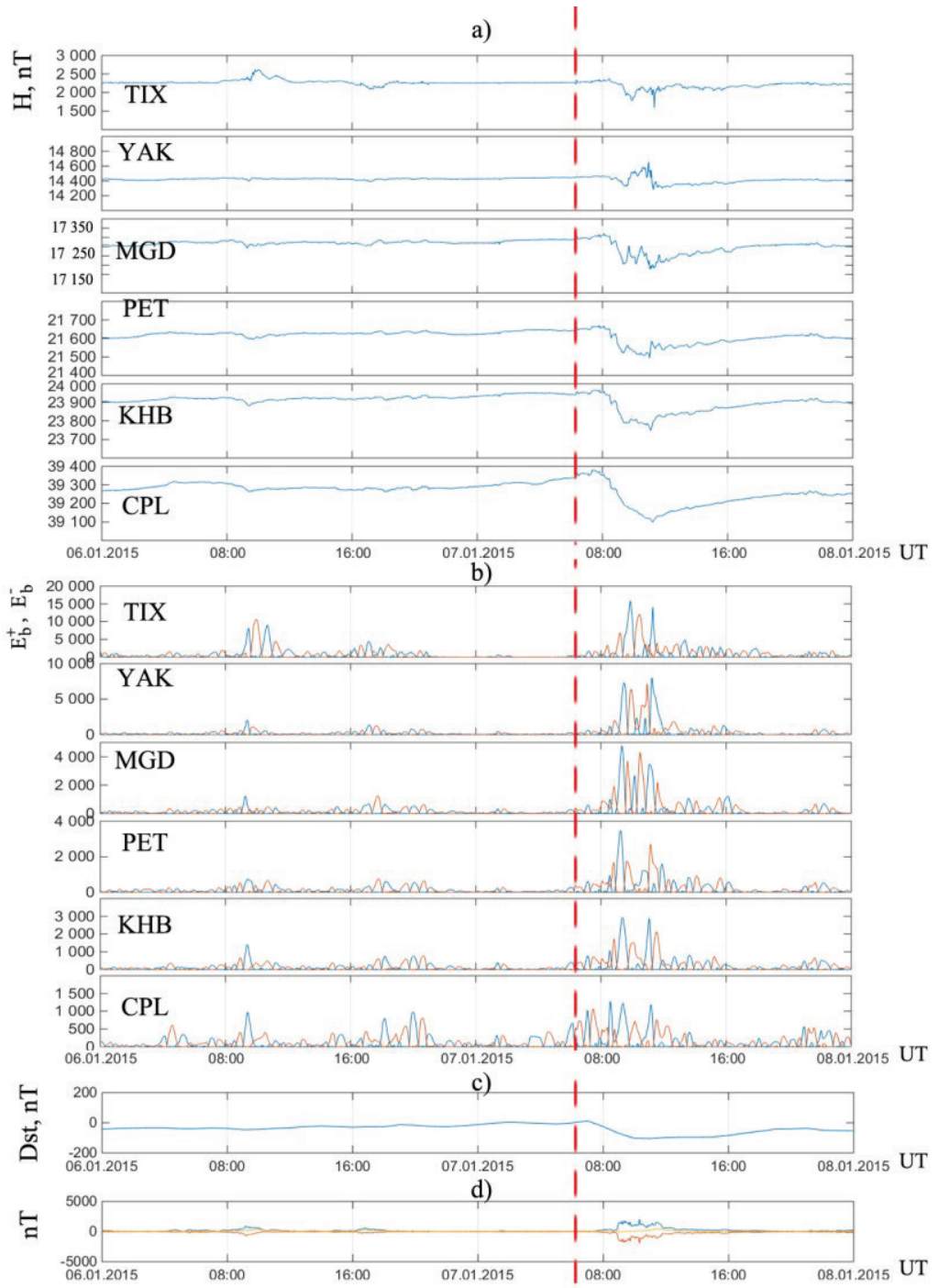

Fig. 5 Results of data processing for January 06-08, 2015: a) H-components of the Earth's magnetic field; b) geomagnetic disturbances intensity, based on the eq. (1), (5) (positive disturbances are indicated by red line, and negative disturbances are indicated by blue line); c) Dst-variation; and d) AE-indices (blue line), AU (yellow line), AL (red line). The dashed line indicates the beginning of the magnetic storm 

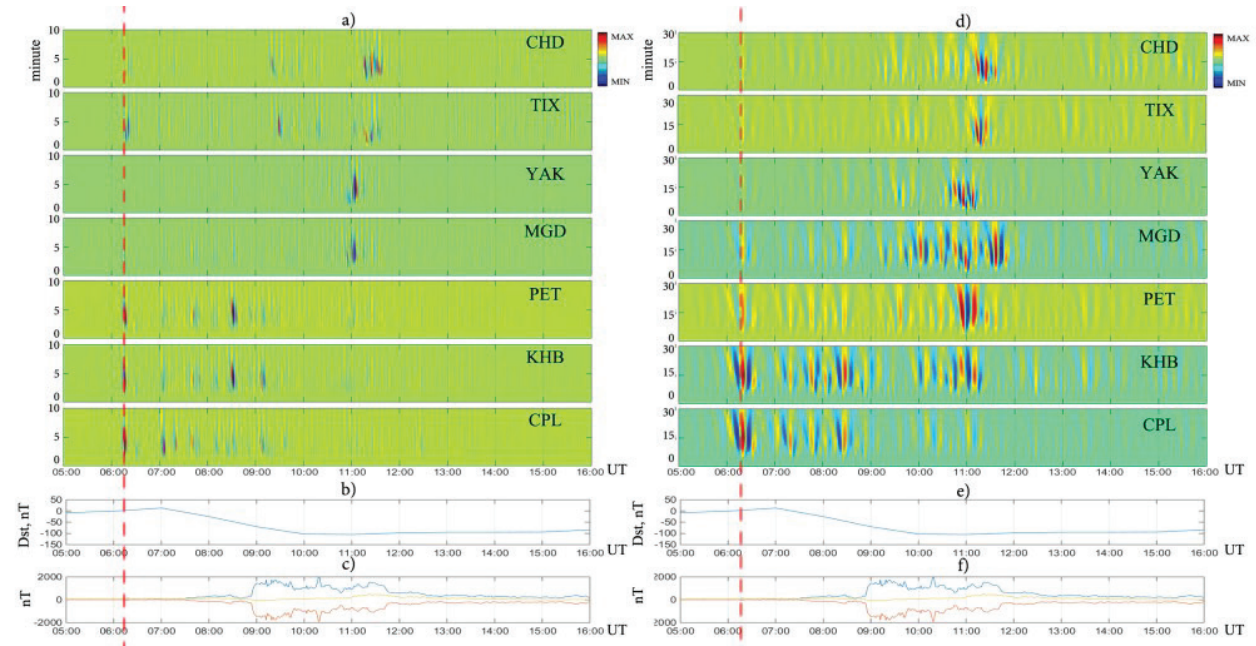

Fig. 6 Results of data processing for January 7, 2015 from 05:00 UT to 16:00 UT a) waveletspectrum of Pi2 pulsations; b) Dst-index; c) AE-indices (blue line), AU (yellow line), AL (red line); d) wavelet-spectrum of Pi3 pulsations; e) Dst-index; and f) AE-indices (blue line), AU (yellow line), AL (red line). The dashed line indicates the beginning of the magnetic storm

The wavelet spectrum of geomagnetic disturbance intensities presented in Fig. 7 (wavelet portrait of the storm) shows a complete pattern of the disturbance dynamics in the analyzed regions during the event period. Analysis shows that during the storm the disturbance dynamics had a general character, which probably characterizes large-scale processes in the magnetosphere (accumulation, redistribution and energy release). During the initial phase of the storm, the strongest disturbances in a wide frequency range (periods of oscillations from a few seconds to several hours) are observed at the equatorial station CPL. During the main phase of the storm, the most active three periods are clearly distinguished. Positive high-intensity disturbances (in Fig. 7a in red) are observed at the equatorial CPL station from 7:00 UT to 8:30 UT. They occur at mid-latitudes (YAK, MGD, PET, KHB stations) with a time shift of about half an hour, and then they occur at high latitudes (stations CHD and TIX) with a shift of another half an hour. The disturbance spectrum has a complex structure; an increase in the amplitudes, an expansion and a shift of the spectrum into the high-frequency region are observed, that it is probably due to the accumulation of energy in the magnetosphere and its discharge at the moments of extremes. Negative disturbances, the space-time distribution of which has a similar character, appeared at the equatorial station CPL (Fig. 7a, blue color) from 8:30 UT. The third active period is characterized by positive disturbances that occur approximately at 9:30 am at the stations near the auroral zone (PET, MGD, YAK stations). Further, they shift to the near equatorial latitude (with a delay of about $15 \mathrm{~min}$ ) and high latitude (with a delay of about 30 minutes). Moreover, the following local features were detected in the wavelet portrait of the storm. Local active processes (Fig. 7a, dotted line), which coincide with variations in IMF small amplitude, are observed at the equatorial region (CLP station) from 7:00 to 9:00. Active regions (Fig. 7, dashed line), which are obviously related to the processes in the auroral zone, are also detected at MGD and YAK stations from 9:30 to 10:30. During the period of increasing values of $\mathrm{AE}$ and $\mathrm{AL}$ indexes, the strongest disturbances of a wide range of frequencies (oscillation periods from several seconds to several hours) occurred at high latitudes (CHD and TIX stations). 


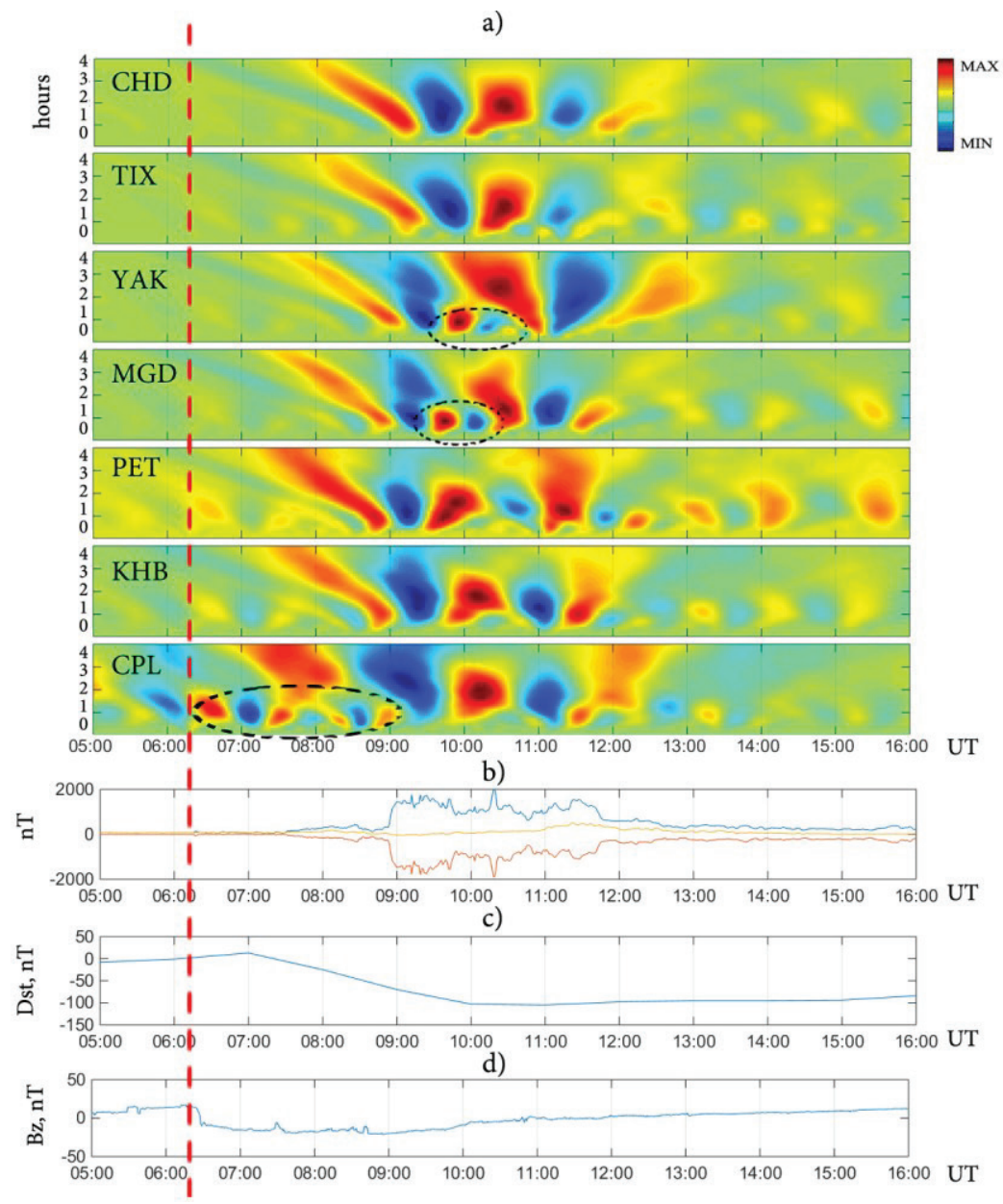

Fig. 7 Results of data processing for January 7, 2015 from 05:00 UT to 16:00 UT a) waveletspectrum of geomagnetic disturbances intensity; b) AE-indices (blue line), AU (yellow line), AL (red line); c) Dst-variation; and d) Bz-component of the interplanetary magnetic field (satellite ACE). The dashed line indicates the beginning of the magnetic storm

To analysis the small-scale short-period variations (from several seconds to tens of minutes) of the geomagnetic field, we used the operation (1) with the values for the parameters of the threshold function of $l=1440$ samples, which corresponds to 24 hours, and $U=7$. Fig. 8 shows the results of this operation on the eve and during the event on January 7, 2015. Analysis of the results shows that on the eve of the magnetic storm on January 6, 2015 from 09:20 to 18:10 UT, short-term increases in geomagnetic activity occurred simultaneously at the stations under analysis (Figure 8). According to space weather data (http://ipg.geospace.ru/space-weather-review/), several small leaps of the solar wind speed, caused by an accelerated stream of solar wind from the coronal hole, were recorded at the beginning of the day of January 5. The solar wind speed varied between 400 and $600 \mathrm{~km} / \mathrm{sec}$, and the Bz component was within $\pm 10 \mathrm{nT}$. According to the data of midlatitude stations, the geomagnetic field was calm on the 5th and 6th of January (http://ipg.geospace.ru/space-weather-review/). The comparison of detected anomalous preincreases with the data of auroral activity shows that the values of AE and AL indices were increased at these instants. Taking into account the data of space weather, the synchronous 
occurrence of this effect at various stations and the simultaneous increase in geomagnetic activity in the auroral zone, it is possible to assume with high probability the solar nature of this effect and the possible connection with the approaching magnetic storm. It can also be noted, that the intensity of the pre-increases grew up in the direction from high latitudes to the equator, and at the equatorial station CPL. The intensity of the pre-increases exceeds the intensity of geomagnetic disturbances in a given frequency range during the event. The results presented in Table 2 also confirm the possibility of anomalous increases in geomagnetic activity on the eve of magnetic storms.

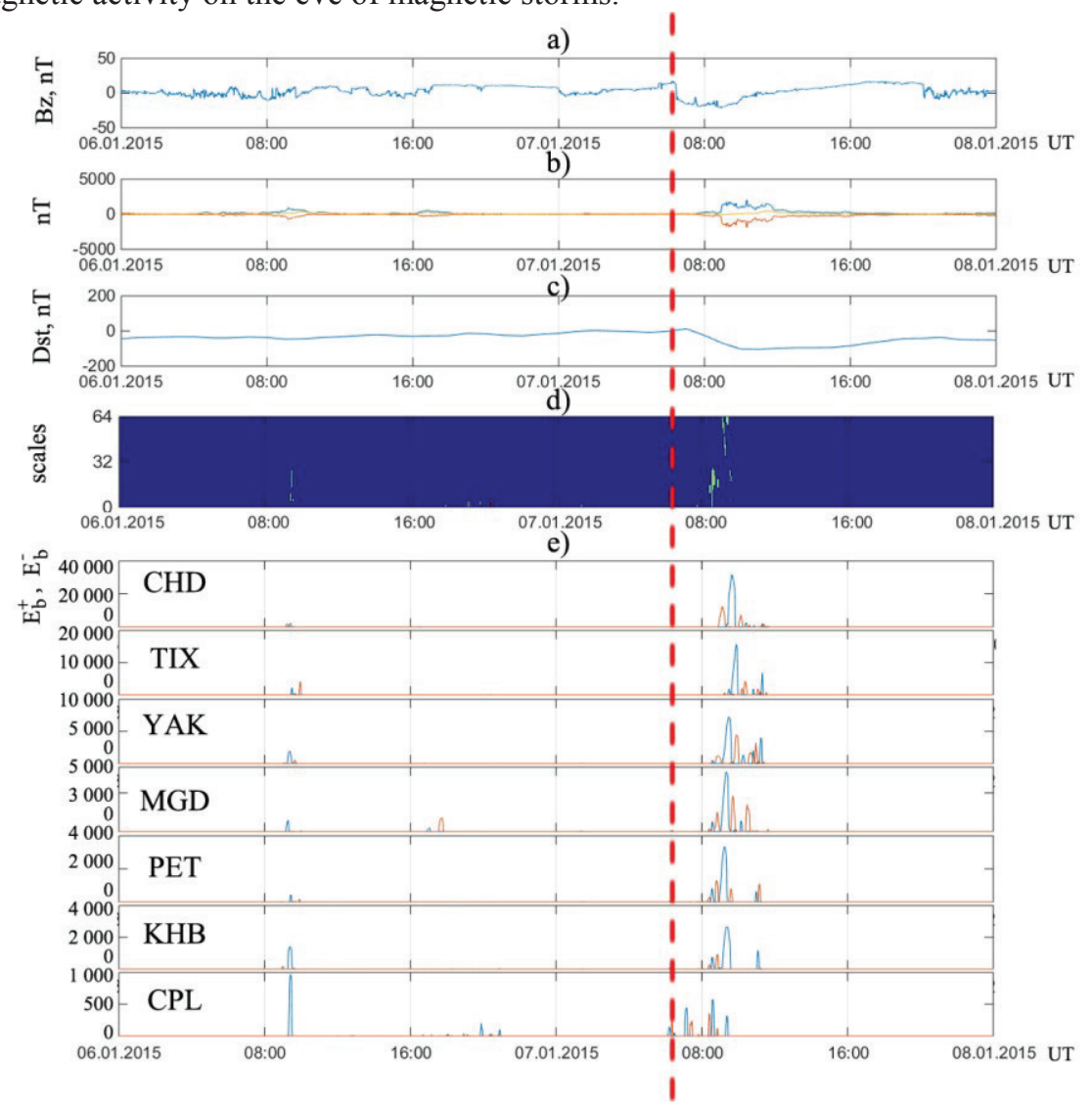

Fig. 8 Results of the data processing for January 06-08, 2015: a) Bz-component of the interplanetary magnetic field (satellite ACE); b) AE-indices (blue line), AU (yellow line), AL (red line); c) Dstvariation; d) detected synchronous increases in geomagnetic activity (using the operations (1)); and e) the intensity of increases in geomagnetic activity (using the operations (1), (5)). The dashed line indicates the beginning of the magnetic storm

Table 2. Results of the data processing during magnetic storms, which occurred in 2015

\begin{tabular}{|l|c|c|c|c|c|}
\hline $\begin{array}{l}\text { Date of a } \\
\text { storm }\end{array}$ & $\begin{array}{c}\text { Storm } \\
\text { source }\end{array}$ & $\begin{array}{c}\text { Time of storm } \\
\text { beginning (UT) }\end{array}$ & $\begin{array}{c}\text { Kp } \\
\mathbf{m a x}\end{array}$ & $\begin{array}{c}\text { Dst } \\
\mathbf{m a x}\end{array}$ & $\begin{array}{c}\text { Anomalies detected before } \\
\mathbf{a} \text { magnetic storm }\end{array}$ \\
\cline { 4 - 6 } & & & & & $\begin{array}{c}\text { Time interval before a } \\
\text { magnetic storm beginning }\end{array}$ \\
\hline 07.01 .2015 & CME & $6: 15$ & 6 & -103 & 21 hours \\
\cline { 5 - 6 } & & & & & 12 hours 10 minutes \\
\hline
\end{tabular}




\begin{tabular}{|c|c|c|c|c|c|}
\hline & & & & & 4 hours 55 minutes \\
\hline \multirow{3}{*}{17.03 .2015} & \multirow{3}{*}{ CME } & \multirow[t]{3}{*}{$4: 45$} & \multirow[t]{3}{*}{8} & \multirow[t]{3}{*}{-233} & 16 hours 30 minutes \\
\hline & & & & & 12 hours 10 minutes \\
\hline & & & & & 11 hours 15 minutes \\
\hline \multirow[t]{2}{*}{21.06 .2015} & \multirow[t]{2}{*}{$\mathrm{CIR} / \mathrm{CME}$} & \multirow[t]{2}{*}{$16: 55$} & \multirow[t]{2}{*}{8} & \multirow[t]{2}{*}{-111} & 10 hours \\
\hline & & & & & 7 hours \\
\hline \multirow[t]{4}{*}{19.12 .2015} & \multirow[t]{4}{*}{ CME } & \multirow[t]{4}{*}{$16: 18$} & \multirow[t]{4}{*}{7} & \multirow[t]{4}{*}{-170} & 25 hours 30 minutes \\
\hline & & & & & 15 hours 30 minutes \\
\hline & & & & & 7 hours 20 minutes \\
\hline & & & & & 1 hour \\
\hline
\end{tabular}

\section{Conclusions}

On the example of the event on January 7, 2015, the paper demonstrates that the proposed method makes it possible to perform a detailed spatio-temporal analysis of magnetic storms from geomagnetic data and to identify both large-scale processes in the magnetosphere and local dynamic features of events. The advantage of the proposed method is also its numerical implementation and the possibility of obtaining accurate quantitative estimates. The analysis of geomagnetic field variations, performed by the station network data during the magnetic storm on January 7, 2015, showed the presence of a general nature of the processes in the analyzed areas. At the initial phase of the storm, the strongest disturbances were observed at the stations located near the equator. During the main phase of the storm, geomagnetic disturbances reached their maximum values. During the periods of increasing values of $\mathrm{AE}$ and $\mathrm{AL}$ indexes, the strongest disturbances were observed at the stations of the auroral and high latitudinal zones. Moreover, local features, probably characterizing the processes in the auroral zone and in the equatorial region, were detected in the disturbance intensity spectrum.

In the opinion of the authors, the short-term increases in geomagnetic activity, detected on the eve of events and occurring synchronously at stations from high latitudes to the equator, are important. Similar pre-increases of geomagnetic activity were noted by the authors in the papers $[6,24]$. Studies of this work confirm the possibility of anomalous increases in geomagnetic activity on the eve of magnetic storms.

Taking into account the limited amount of information on the state of the near-Earth space, the presence of noise, possible hardware failures, etc., application of geomagnetic data recorded on the earth's surface is important for the tasks of space weather forecast.

The development of the method for geomagnetic data analysis was supported by RNF Grant No. 14-11-00194. The primary analysis of the data was supported by RFBR Grant No. 16-55-45007. The authors are grateful to the institutions supporting magnetic observatories whose data were used in the study.

\section{References}

1. Yu.I. Yermolaev, M.Yu. Yermolaev, IZV ATMOS OCEAN PHY+, 46(7), 799-819 (2010)

2. S.R.P. Nayar, V.N. Radhika, P.T. Seena, ILWS2006, 328-331 (2006)

3. A.G. Hafez, E. Ghamry, H. Yayama, K. Yumoto, ASR, 51, 39-49 (2013) 
4. Z. Xu, L. Zhu, J. Sojka, P. Kokoszka, A. Jach, J. Atmos. Solar-Terr. Phys., 70, 15791588 (2008)

5. Jach, P. Kokoszka, J. Sojka, L. Zhu, J. Geophys. Res., 111(A9) doi:10.1029/2006JA011635 (2006)

6. P. Paschalis, C. Sarlanis, H. Mavromichalaki, Sol. Phys., 182(1), 303-318 (2013)

7. K.P. Macpherson, A.J. Conway, J.C. Brown, J. Geophys. Res., 100, 735-744 (2001)

8. J.W. Woolley, P.K. Agarwarl, J. Baker, International Journal for Numerical Methods in Fluids, 63, doi:10.1002/fld.2117 (2010)

9. Soloviev, A. Chulliat, S. Bogoutdinov, A. Gvishiani, S. Agayan, A. Peltier, B. Heumez, EPS, 64(9), 743-752, (2012)

10. N. Rotanova, T. Bondar, V. Ivanov, Geomagn. Aeron., 44, 252-258 (2004)

11. J. Rybàk, A. Antalovà, M. Storini, Space Sci. Rev., 97 359-362 (2001)

12. N. Zaourar, M. Hamoudi, M. Mandea, G. Balasis, M. Holschneider, EPS, 65(12), 1525-1540 (2013)

13. A.S. Smirnova, S.D. Snegirev, O.A. Sheyner, Vestnik of Lobachevsky University of Nizhni Novgorod, 6(1), 88-93 (2013)

14. O.V. Mandrikova, I.S. Solovev, T.L. Zalyaev, EPS, 66. doi:10.1186/s40623-014-01480 (2014)

15. V.P. Golovkov, V.O. Papitashvili, N.E. Papitashvili, Geomagn. Aeron. , 29, 667-670. (1989)

16. K. Nowożyński, T. Ernst, J. Jankowski, Geophys. J. Int., 104, 85-93 (1991)

17. M. Menvielle, N. Papitashvili, L. Hakkinen, C. Sucksdorff, Geophys. J. Int., 123, 866886. (1995)

18. O.V. Mandrikova, S.E. Smirnov, I.S. Solov'ev, Geomagn. Aeron., 52(1), 111-120 (2012)

19. S.R. Bogoutdinov, A.D. Gvishiani, S.M. Agayan, A.A. Solovyev, E. Kihn, Izvestiya, Physics of the Solid Earth, 46 (11), 1004-1016 (2010)

20. R.V. Sidorov, A.A. Soloviev, Sh.R. Bogoutdinov, Izvestiya, Physics of the Solid Earth, 48(5), 410-414 (2012)

21. R. I. Krasnoperov, A.A. Soloviev, Gornyi Zhurnal 10, 89-93, doi: 10.17580/gzh.2015.10.16 (2015)

22. Soloviev, S. Bogoutdinov, A. Gvishiani, R. Kulchinskiy, J. Zlotnicki, Data Science Journal, 12, doi:10.2481/dsj.WDS-019 (2013)

23. J. Uwamahoro, L.A. McKinnell, J.B. Habarulema, ANGEO, 30, 963-972 (2012)

24. Mahrous, A. Radi, M. Youssef, A. Faheem, S. Ahmed, N. Gopalswamy, COSPAR, D23-0052-10 (2010)

25. G. Pallocchia, E. Amata, G. Consolini, M. F. Marcucci, I. Bertello, ANGEO, 24, 989999 (2006)

26. O.V Mandrikova, Problems of the evolution of open systems, 2(10), 161-172 (2008, in russian)

27. O.V. Mandrikova, Yu.A. Polozov, Information technologies, 7, 61-65 (2014, in russian)

28. V.V. Geppener, O.V. Mandrikova, E.A. Zhizhikina, SCM'2015, 251-254, Doi: $10.1109 / \mathrm{scm} .2015 .7190473$ (2015) 
29. O.V. Mandrikova, E.A. Zhizhikina, Computer Optics, 39(3), 420-428 (2015, in russian)

30. O.V. Mandrikova, I. Solovjev, V.V. Geppenerc, A-KR. Taha, D. Klionskiy, DIGIT SIGNAL PROCESS, 23, 329-339 (2013)

31. C.K. Chui An introduction in wavelets (Academic Press, 1992)

32. Daubechies Ten Lectures on Wavelets (CBMS-NSF Lecture Notes nr. 61, 1992)

33. O.A. Sheiner, V.M. Fridman, Radiophys Quantum El., 54(10), 655-666 (2012)

34. O.V. Mandrikova, V.V. Bogdanov, I.S. Solov'ev, Geomagn. Aeron., 53(2), 268-273. (2013) 